\title{
A Diplomacia Triangular: Nixon, Kissinger e a China
}

\section{Jorge Arbage *}

DOI: 10.11606/issn.2318-8855.v10i2p89-120

Resumo: Até 1969, um aperto de mãos entre Mao Zedong e Richard Nixon era improvável até nos mais absurdos sonhos. Um contrassenso, podia-se dizer. Mas, apenas três anos depois, o inimaginável se tornou realidade. A aproximação entre Estados Unidos e República Popular da China foi um evento que não somente abalou, mas moldou o mundo. Aqui, por meio do olhar da história da diplomacia, buscaremos compreender como se deu esse processo: quais os papéis dos principais atores, qual era o contexto geopolítico de 1969, o que levou à esta aproximação improvável, como ela foi feita e como se deram as estratégias da Diplomacia Triangular e da Détente.

Palavras-chaves: Détente, Diplomacia Triangular, Kissinger, Nixon, Relações Estados Unidos - China.

* Graduando em História: Faculdade de Filosofia, Letras e Ciências Humanas - Universidade de São Paulo. E-mail: Jorge.brito@usp.br 


\section{artigos}

Jorge Arbage

\section{Introdução}

Richard Nixon era um homem complexo e múltiplo. Poucas figuras foram tão enigmáticas, de caráter tão profundo e hermético. Seu governo foi um dos momentos mais notórios da diplomacia; ao mesmo tempo, este mesmo governo foi uma máquina de abuso de poder e chantagens políticas desenfreadas que, eventualmente, levaram à sua ruína. Nixon tinha a grandeza e o tormento: era capaz de realizar movimentos ousados, moldar o mundo, escrever a história; da mesma forma, também era capaz de pequenos e mesquinhos atos de vingança e violência política. "Um dos mais hábeis líderes geopolíticos" de nossos tempos, Gaddis diria, "foi também o presidente americano menos disposto - em toda a história - a respeitar os limites de sua própria autoridade" (GADDIS, 2005, p.171).

Divergências à parte, é preciso reconhecer que foi este mesmo homem motivo de tantas chacotas e vilipêndias - quem deu fim à participação americana na guerra do Vietnã e ao alistamento obrigatório, quem iniciou um período de paz com a União Soviética, lançou a Détente e iniciou as relações diplomáticas com a "China Vermelha". Ninguém poderia imaginar que, um dia, Richard Nixon não somente iria às capitais da República Popular da China e da União Soviética (o primeiro presidente na história dos EUA a fazê-lo), como também apertaria as mãos de Mao Zedong.

O impensável se tornara realidade. Se observamos o passado de ambos, é um encontro surpreendente, tão improvável a ponto de o hermético Nixon se expor em um breve e íntimo momento de reflexão, no qual demonstrou certa melancolia. Diante de Mao, o presidente meditou sobre o extraordinário fato de ambos estarem ali, reunidos naquele momento:

A vida do Chairman [Mao] é bem conhecida a todos nós. Ele veio de uma 


\section{artigos}

\section{A diplomacia triangular}

família pobre e foi ao topo da nação mais populosa do mundo, uma grande nação. Já o meu passado não é tão conhecido. Eu também vim de uma família pobre e fui ao topo de uma grande nação. A história nos uniu... (DOCUMENT 194, 1972; tradução nossa).

Como pouquíssimos chefes de estado ao longo da história, ele teve uma extraordinária visão da ordem mundial e do balanço de poder entre as nações. Esta é, aliás, uma característica marcante em sua visão de mundo. Para Richard Nixon, a função do presidente era, acima de tudo, lidar com política externa e geopolítica global. Consequentemente, ninguém lhe seria mais próximo e necessário que Henry Kissinger; não à toa, a relação entre os dois adquiriu status antológico.

No entanto, era preciso um ponto de partida para poder moldar o mundo por meio da política externa e, em 1969, toda a questão da geopolítica global e do papel americano girava em torno de uma única palavra: Vietnã.

"Se nós fracassarmos no Sudeste Asiático", Nixon disse em março, "este país sofrerá um golpe do qual nunca mais irá se recuperar como potência global..." (DALLEK, 2007, p.261; tradução nossa). Para o presidente, o Vietnã era mais que uma guerra controversa; a guerra no Sudeste Asiático também representava o rearranjo da ordem global. A grande pergunta era: qual papel os Estados Unidos iriam assumir em um mundo pós-Vietnã? Quarenta anos depois, Kissinger escreveria:

Nixon sabia que, independentemente da agonia do envolvimento no Vietnã, os Estados Unidos permaneciam sendo o país mais forte em uma aliança contra a agressão comunista pelo mundo afora, e que a credibilidade americana era crítica. O governo Nixon desse modo buscou uma retirada planejada da Indochina para dar ao povo da região uma oportunidade de moldar seu próprio futuro e sustentar a fé mundial no papel americano. [...] Nixon estava comprometido a pôr um fim à guerra, mas igualmente determinado a fornecer ao país um papel dinâmico em reformar a ordem internacional... (KISSINGER, 2011, p.217; ênfase nossa). 


\section{artigos}

Jorge Arbage

Para o diplomata, o verdadeiro objetivo era "criar uma realidade política que pudesse sobreviver à retirada americana" e, desta forma, transformar o fracasso na Indochina em sucesso por meio da criação de um novo arranjo de poder. Ele pensava que, ao tomar as rédeas da inevitável mudança da ordem global que ocorreria com a retirada, poder-se-ia gerar "uma oportunidade de redefinir a abordagem americana da política externa e da liderança internacional" (Kissinger, 2011b, p.232; 2011, p.217).

O Vietnã era, pois, a espada de Dâmocles, tanto a peça central quanto o calcanhar de Aquiles da nova administração. Aos olhos da Casa Branca, ele representava uma imensurável fraqueza na habilidade dos Estados Unidos instigarem confiança em seus aliados e respeito em seus inimigos. Estes eram valores inegociáveis para os americanos, que levavam muito a sério a "credibilidade e a honra", posto que "elas determinariam a capacidade americana de moldar uma ordem internacional pacífica" (KISSINGER, 2012, p.626). Com os comunistas era preciso ser firme, pois eles entendiam somente a "força" e a "resolução" (DOCUMENT 193, 1972). Como Hitchens escreve,

Se Kissinger e seu patrão Nixon fossem identificados com alguma crença básica, seria de que os Estados Unidos nunca deveriam ser, ou parecer ser, um piedoso e indefeso gigante. Os próprios escritos de Kissinger e seus discursos são carregados com a retórica sobre "credibilidade" e a necessidade de impressionar amigos e inimigos com o brio da resolução norte americana (HITCHENS, 2002, pp.127,128).

Sob este ponto de vista, era preciso, portanto, primeiro resolver a questão da Guerra para, então, buscar alianças com União Soviética e China. Mas a história seguiria outros rumos; ao final, as estradas rumo a Pequim e a Moscou não passavam por Hanói. Ocorreu justamente o oposto: a escalada do insucesso estadunidense no Vietnã coincidiu com o estreitamento de suas relações com as duas grandes potências (VAÏSSE, 2013). Houve uma inversão da tendência a qual se acreditava 


\section{artigos}

\section{A diplomacia triangular}

inicialmente ${ }^{1}$ : as alianças com China e URSS, ao isolar Hanói, terminariam por ajudar os EUA a sair do Vietnã e não o contrário.

Atribui-se a Sun Tzu a famosa frase: "Oportunidades são multiplicadas à medida que são agarradas". Nas duas capitais, Washington e Pequim, a frase foi levada a sério. Grandes potências jamais agem contra seus próprios interesses. Se naquele determinado momento histórico Estados Unidos e República Popular da China realizaram uma aproximação improvável, é porque ela favorecia a ambos: era o "reconhecimento de uma nova situação global" (DOCUMENT 194, 1972; tradução nossa).

Podemos dizer que o sentimento era recíproco. Assim como os americanos, os dirigentes chineses perceberam a necessidade de reavaliar sua posição e buscar novos aliados. Esta nova percepção, porém, só se originou após uma série de choques e rupturas, cujo mais importante é o nosso ponto de partida: o racha SinoSoviético, o cerne da Diplomacia Triangular.

\section{A Ruptura Sino-Soviética}

Em meados de março de 1969, China e União Soviética, as duas maiores potências do mundo comunista, se enfrentaram em um violento conflito fronteiriço não declarado às margens do rio Ussuri. Com mais de 6.500 quilômetros, a fronteira sino-soviética não era somente a maior, mas também uma das mais militarizadas do mundo. Seis anos antes, em março de 1963, o governo de Pequim declarou não reconhecer a sua legitimidade, alegando que a fronteira fora delimitada por "tratados desiguais" (FENKELSTEIN, 1978). Até então, este era um tema de menor importância e é evidente que a mudança do posicionamento de Pequim está relacionada a uma

\footnotetext{
1 Para mais sobre a relação entre Vietnã e a aliança com Pequim, ver: Kissinger (2012); Kissinger (2011b), p.164; Dallek (2007), p.372; Karnow (1983), p.598; MacMillan (2008), p.xxi; Vaïsse (2013), p.99.
} 


\section{artigos}

Jorge Arbage

divergência ideológica (GERSON, 2010).

Verdade seja dita, a relação entre os dois gigantes socialistas nunca foi fácil. É fato que, nos primeiros anos, ambos os lados buscaram apagar de suas histórias as inimizades - Mao, por exemplo, chegaria a alegar que "é um grande acontecimento o fato de a humanidade possuir um Stálin" (PO-TA, 2017, p. 57). O PCCh, aliás, publicaria uma obra oficial escrita por Chen Po-Ta a respeito da suposta contribuição de Stalin à Revolução Chinesa - gentilezas que, com o passar do tempo, se tornariam cada vez mais raras.

Mas, ao contrário do que a obra de Po-Ta alega, Stalin jamais demonstrou grande interesse na revolução chinesa e mesmo quando esta se encaminhava rumo a seu triunfo, manteve distância do líder chinês. Schram chegou inclusive a dizer que Stalin não havia contribuído em nada para a ascensão de Mao, e que sua "convicção simplista" sobre a China "levou a Revolução Chinesa a repetidas catástrofes que os líderes chineses, e Mao em particular, nunca mais esqueceram" (SCHRAM, 1968, pp.77, 347).

São muitos os relatos que indicam uma amarga relação entre ambos, o que ficou claro durante a primeira visita do chinês a Moscou, em 1949. Ao final, ele ficou mais de nove semanas na capital até conseguir um tratado de mútua defesa, conquistado, nas palavras de um grande historiador, às custas de "muita humilhação gratuita" (FERGUSON, 2016, p.254; tradução nossa). Para alguns autores, Stalin havia finalmente encontrado uma figura histórica à sua altura, cujo poder e capacidade ameaçavam o poderio soviético, e reagiu a isso com extrema desconfiança.

O conflito na Coréia fez pouco para melhorar a situação. Efetivamente, a agravou ainda mais. Não à toa, Dikötter descreve a morte de Stalin como a 


\section{artigos}

A diplomacia triangular

"libertação" de Mao - um exagero, decerto, embora carregue consigo um elemento de verdade. No entanto, tal "libertação" seria uma faca de dois gumes. "Mao tinha ressentimentos de Stalin", Service escreve (2010, p. 595; tradução nossa), "mas pensava que as reformas de Khrushchev eram uma ruptura muito grande com o tipo de comunismo defendido por ambos...".

A relação, pois, não seria mais a mesma. Logo em seu primeiro ano no poder, Khrushchev declarou que o conflito com a China era inevitável (GERSON, 2010). A partir de 1962, China e União Soviética eram inimigos irreconciliáveis. Pela primeira vez desde 1917, uma outra potência do mundo comunista clamava para si o título de líder global do movimento revolucionário. A declaração de Mao, feita após a assinatura do tratado de amizade sino-soviético, de que a amizade entre os dois era “eterna e indestrutível", foi carregada feito pó pelos ventos da história...

\section{Um pária para a comunidade global}

Para Perry Anderson, a Revolução Cultural tratou-se, sobretudo, "de uma tentativa radical de sacudir as estruturas burocráticas" (ANDERSON, 2018, pp. 32, 34). Em apenas uma década, Mao mergulhou seu país em uma série de "mergulhos cataclísmicos", movidos por uma sede insaciável de transformação e impermanência (HOBSBAWM, 2015, p.452). Era, em essência, uma guerra contra o aparelho estatal, uma guerra purificadora, cujo inimigo era o mundo velho, pútrido, enrijecido. Em suma, tratava-se da Revolução Permanente. "Para ele, lutar era um fim", Nixon escreveria em suas memórias, "e não um meio para atingir um fim" (NIXON, 1991, p.118; tradução nossa).

Ora, em um movimento que buscou sacudir as estruturas burocráticas, para utilizar a expressão de Hobsbawm, é evidente que o corpo diplomático chinês seria 


\section{artigos}

Jorge Arbage

atingido, dado que a diplomacia é a profissão burocrática estatal per se. Não será, pois, surpresa alguma observarmos que absolutamente toda a diplomacia chinesa foi afetada pela Revolução Cultural.

Em Pequim, os ecos dos Boxers atravessavam as camadas do tempo, as representações estrangeiras e seus delegados eram vítimas do ímpeto revolucionário dos Guardas Vermelhos (INTELLIGENCE..., 1968). A embaixada da Inglaterra foi atacada e a da Indonésia, engolida por chamas. O desprezo maior, no entanto, foi reservado aos soviéticos: após saquearem a embaixada, os guardas vermelhos expulsaram seus funcionários de forma humilhante, forçando-os a deixar a China a pauladas, tendo de beijar pôsteres de Mao até os aviões.

Enquanto isso, no estrangeiro, mais da metade do corpo diplomático foi convocado de volta à China para "reeducação". Como se vê, após a Revolução Cultural, absolutamente todas as representações diplomáticas - as chinesas no exterior e vice-versa - haviam sido afetadas. O país estava isolado do mundo, literalmente. Tal convulsão revolucionária foi o zênite de uma década de turbulência e catástrofes. Na virada dos anos 1950 e 1960, a China se envolveu em uma série de conflitos que foram, gradualmente, isolando-a da comunidade global. Primeiro, duas crises no Estreito de Taiwan; pouco depois, ao sul da fronteira, uma breve guerra contra a Índia. Ao mesmo tempo, as relações com Moscou se rompiam em definitivo. Por fim, a Revolução Cultural.

Estados Unidos, Índia, URSS... a lista de inimigos se agigantava de tal forma que, em 1969, o governo de Pequim se viu como um pária. Como no tempo dos imperadores, o Império do Meio encontrava-se não somente isolado, mas também cercado por poderosos inimigos que desejavam, cada um à sua maneira, um pedaço 


\section{artigos}

A diplomacia triangular

do país.

\section{Nixon e Kissinger}

Do outro lado do mundo, após anos de ostracismo político, Nixon retornou à arena política. Sua ascensão à presidência marcou uma transformação completa na geopolítica estadunidense. O novo presidente observara com atenção os erros de seus predecessores, especialmente no Vietnã. Notou, também, a perda da hegemonia de seu país diante dos ressurgimentos econômicos europeu e japonês.

"O agonizante processo de extrair os americanos do Vietnã", Kissinger escreve, “tem relação em manter a posição dos Estados Unidos no mundo. [...] Foi, enfim, o sinal de que estava mais do que na hora de reavaliar seu papel..." (KISSINGER, 2012, p.653; a ênfase é nossa). Para Nixon, esta nova abordagem não se tratava de uma fórmula para tirar a América da Ásia, mas a única forma da nação permanecer e continuar desempenhando um papel responsável no continente. A epítome deste pensamento seria sua frase dita a Mao: “Em relações internacionais não há boas escolhas. Uma coisa é certa - não se pode deixar vácuos, pois eles podem ser preenchidos" (KARNOW, 1983, p.609; DOCUMENT 194, 1972; tradução nossa).

Com a ascensão de Nixon e Kissinger, o idealismo encontrou seu fim. Após anos de radicalismo ideológico, a Realpolitik batia às portas da Casa Branca. Era o início de uma transformação completa na geopolítica estadunidense, a chamada Doutrina Guam². A doutrina prezava uma nova forma de os Estados Unidos agirem perante as outras nações - se reconhecia a problemática envolvida em intervir militarmente em territórios distantes, como fora parte da Política da Contenção. Agora, buscava-se um papel mais realista e equilibrado. Acima de tudo, a nova

\footnotetext{
2 Doutrina Nixon.
} 


\section{artigos}

Jorge Arbage

administração removeu da política externa americana aquilo que Kissinger chamou de uma visão "teológica", isto é, a condenação moral dos adversários. Na nova doutrina de Nixon, a política interna de uma nação deixava de ser um fator tão relevante. Como ele disse a Mao Zedong:

O que nos une é o reconhecimento de uma nova situação global, o reconhecimento de que o importante não é a política filosófica interna de uma nação, mas sua política em relação ao resto do mundo... (DOCUMENT 194, 1972; tradução e ênfase nossas).

A ideia de abandonar o idealismo, "a política filosófica", e esboçar uma aproximação com a China não era nova, embora fosse revolucionária. Em 1962, ano da ruptura sino-soviética, Kissinger já a havia explorado em um estudo para Rockfeller (FERGUSON, 2016). Na mesma época, durante seu interlúdio como estadista aposentado, Nixon ouviu do chanceler filipino, Carlos Romulo, que as portas para uma aliança chinesa estavam se abrindo, e ouviria isso novamente ao se encontrar com De Gaulle, em fevereiro de 1969 (NIXON, 1991; Kissinger, 2011b).

Antes mesmo de eleito, Nixon já captara a importância da ruptura entre os gigantes comunistas. No meio da década, ele havia constatado que a China comunista era fait accompli. Em um artigo escrito para a Foreign Affairs de outubro de 1967, ele escreveu:

A longo prazo, nós simplesmente não podemos deixar a China eternamente fora da família das nações [...]. Não há lugar neste pequeno planeta para que um bilhão de pessoas vivam em raivoso isolamento... [Angry Isolation] (NIXON, 1967; a tradução é nossa).

Meses depois, durante seu discurso de inauguração, o presidente enviou mais um discreto sinal, repetindo os termos do artigo. Falou em "uma nova era", uma "era negociações", um "mundo aberto", no qual nenhum povo viveria em "angry isolation" 


\section{artigos}

\section{A diplomacia triangular}

(NIXON, 1969). É de se notar o quanto a China se tornara importante para a política do novo governo. As anotações daquele mesmo dia, seu primeiro como presidente, indicam que ela foi tema importante em suas reuniões. É possível encontrar anotações escritas à mão por Nixon: "Comunistas chineses: curto prazo - nenhuma mudança. Longo prazo - não queremos 800,000,000 vivendo em raivoso isolamento". Alguns dias depois, em 1 de fevereiro, um memorando indicava uma tentativa de contatos com os chineses. No mesmo documento, Kissinger incentiva a reaproximação, mas alerta para seus perigos: "Isto, é claro, deve ser feito de forma privada e não deve, sob circunstancia alguma, ser divulgado ao público..." (DOCUMENT 3, 1969; tradução nossa).

Havia razão para tais temores: aquele era um tema absolutamente frágil e sensível para a política estadunidense; o caminho rumo a Pequim era uma corda bamba e sinuosa. Além da opinião pública, havia os riscos internacionais. Como o Japão reagiria? E se os russos descobrissem? Todo o esforço de Washington em se reunir com Moscou para selar os acordos SALT poderia vir por água abaixo, caso os soviéticos enxergassem a aproximação com Pequim como uma forma de chantagem ${ }^{3}$. E quanto aos aliados políticos, os conservadores?

Desta forma, diante do público, Nixon oscilava entre pregar uma reaproximação e manter o isolamento. Em outubro de 70, o presidente chegou a dizer publicamente que pretendia visitar a China antes de morrer e, em fevereiro do ano seguinte, escreveu em seu relatório anual sobre política externa que era do interesse "de todo o mundo" incluir "750 milhões de pessoas talentosas e energéticas" em "um relacionamento construtivo com a comunidade mundial". Enquanto isso,

\footnotetext{
3 Em conversa com Zhou Enlai em fevereiro de 1973, Kissinger falou do temor de a aproximação chinesa levar ao radicalismo de Moscou: No final, ele confessa, o julgamento americano foi errado. A aproximação com a URSS acelerou após visita a Pequim: Document 9 (1973).
} 


\section{artigos}

Jorge Arbage

entre uma e outra declaração, disse que não tinha a menor intenção de mudar a política do seu país em relação a Pequim (DALLEK, 2007, pp. 265, 266; tradução nossa).

É preciso mencionar que os chineses também enfrentaram resistência interna. Ao se encontrar com os americanos, Mao mencionou "um grupo reacionário" que se opôs a iniciativa, e lançou ainda mais mistério sobre o caso Lin Biao ao dizer que "eles entraram em um avião e fugiram" (DOCUMENT 194, 1972; tradução nossa). O sigilo, pois, agradava a ambos. Apenas um punhado de pessoas estavam cientes do que se passava. O único país que tinha conhecimento destas conversas era o Paquistão, pois servia como canal de comunicação entre Pequim e Washington. Em resposta à sua confiabilidade, Kissinger agradeceria a Yahya Khan, o general-presidente paquistanês, por sua "delicadeza e tato", uma escolha de palavras que, conforme será apresentado adiante, se mostrará inadequada, até mesmo absurda.

O sucesso deste projeto dependia de um único fator: que chineses e soviéticos temessem mais um ao outro que aos Estados Unidos. Mas grandes potências só agem sob a certeza: foi somente com o conflito armado no Ussuri que a grande questão - quem era mais temido - foi esclarecida. Tendo de priorizar a fronteira chinesa, os soviéticos ficaram debilitados na Europa; os chineses, por sua vez, que já estavam enfraquecidos na Indochina devido ao iminente triunfo vietnamita, se viam agora também ameaçados por Índia e URSS.

De uma só vez, todo o balanço de poder mudou. Abriam-se, assim, as portas para a Diplomacia Triangular: a perda de influência americana na Ásia, devido à 


\title{
artigos
}

\section{A diplomacia triangular}

guerra no Vietnã, poderia ser compensada por uma diplomacia de duas frentes. Aliando-se simultaneamente a dois países inimigos entre si, os Estados Unidos poderiam contrabalancear sua perda de poder e moldar um novo "equilíbrio global"4. A história muitas vezes é feita pelo acaso, pela combinação de pessoas, tempo e lugar certos. Foi o que aconteceu em março de 1969, quando as duas maiores potências do mundo comunista quase entraram em pé de guerra. Kissinger explica:

\begin{abstract}
A política emerge quando o conceito encontra a oportunidade. Essa ocasião surgiu quando tropas chinesas e soviéticas lutaram na congelada tundra siberiana, ao longo de um rio o qual nenhum de nós já tinha ouvido falar. Daquele momento em diante, a ambiguidade desapareceu e nós nos movemos sem hesitar em direção à uma importante mudança na diplomacia global (KISSINGER, 2011b, p.171; ênfase e tradução nossas).
\end{abstract}

Fruto de um realismo puro, calcado no balanço de poder, extirpado de todo sentimentalismo, o conceito da Diplomacia Triangular era essencialmente negociar, em separado, com Moscou e Pequim, de forma a criar este novo equilíbrio; iniciar uma nova era diplomática na qual a inserção de um poderoso terceiro ator na equação, a China, tornava improvável uma guerra e levaria à uma mudança na atitude tensa e militarista da época (KISSINGER, 2011b, pp. 164, 177, 192). Abrir-seiam, então, as portas para um relaxamento das relações entre os países. A Diplomacia Triangular estava, pois, diretamente relacionada ao conceito da Détente. Efetivamente, ambas eram indissociáveis uma da outra.

Tudo isso, no entanto, ainda era somente um ousado projeto de política

\footnotetext{
${ }^{4}$ A imagem de um policymaker diante de uma encruzilhada de opções ingratas, tendo de optar entre dois males, é temática recorrente na oratória tanto de Nixon quanto de Kissinger. Após Mao dizer a Nixon que havia votado nele nas últimas eleições, o presidente respondeu que era o menor dos dois males (DOCUMENT 194, 1972). Duas décadas depois, em seu clássico Diplomacia, Kissinger usaria novamente este pensamento: "A política externa muitas vezes implica escolha entre coisas imperfeitas": Kissinger (2012), p.633.
} 


\section{artigos}

Jorge Arbage

externa, esboçado após os eventos de março, os quais os Estados Unidos tomaram nota. Esta mudança definitiva no status quo, é claro, também não passou despercebida pelos chineses. Em Pequim, eles também chegavam às suas próprias conclusões.

\section{Os estudos chineses: os relatórios dos Quatro Marechais}

Nixon descreveu Mao como um homem "que percebe quando há uma oportunidade, que agarra o momento" (DOCUMENT 194, 1972; tradução nossa). Embora permanecesse cauteloso, Mao notara que uma porta havia sido aberta. Quase que imediatamente, reabilitou quatro marechais expurgados durante a Revolução Cultural e pediu aos quatro a elaboração de um amplo estudo a respeito da política externa chinesa, cuja conclusão inicial foi que EUA e URSS caminhavam cada vez mais à uma posição de confronto. Este estudo alegava que, no caso de um conflito sino-soviético, os americanos não tomariam lado e ficariam, como dizia o antigo ditado chinês, "sentados sobre o topo da montanha, observando os dois tigres brigarem". Havia, conquanto, uma observação muito interessante naquele mesmo documento, indicativa da percepção de que o equilíbrio de poder mudara: "Os revisionistas soviéticos fizeram da China seu maior inimigo, impondo à nós uma ameaça à segurança maior que os Estados Unidos..." (REPORT: JULY 11, 1969; tradução e ênfase nossas).

Este relatório inicial foi revisto em setembro de 1969. Curiosamente, os marechais chegaram simultaneamente à mesma conclusão que a Casa Branca. No mês anterior, durante uma reunião do Conselho de Segurança Nacional, Nixon apresentara a ideia de que era contra os interesses americanos ver a China esmagada em uma guerra sino-soviética (KISSINGER, 2011b). Do mesmo modo, o novo relatório 


\title{
artigos
}

\section{A diplomacia triangular}

chinês alegava que, cedo ou tarde, os Estados Unidos teriam de romper sua posição de expectadores e tomar lado em um possível conflito:

\begin{abstract}
A última coisa que os imperialistas norte-americanos estão dispostos a ver é uma vitória dos revisionistas soviéticos em uma guerra sino-soviética [...]. Os revisionistas soviéticos temem que nós possamos nos aliar aos imperialistas americanos para confrontá-los (REPORT: SEPTEMBER 17, 1969; tradução e ênfase nossas).
\end{abstract}

Aquele documento secreto foi revolucionário, especialmente se tivermos em conta que, em 1969, a nação ainda se encontrava no redemoinho da Revolução Cultural. Pela primeira vez, a China cogitou uma aproximação com seu grande e mortal inimigo. Um dos marechais buscou aliviar o impacto das conclusões, alegando que Nixon parecia estar disposto a mudar os rumos da política estadunidense e propôs, então, uma linha de diálogo oficial com os Estados Unidos.

Isso revela, também, muito sobre a complexidade da análise chinesa. Se observamos o lado chinês da reaproximação, veremos que a imagem de uma nação ideologicamente fanática, irracional e intransigente - como difundida no Ocidente não condiz, de forma alguma, com a realidade. Na verdade, é possível observar uma clara percepção do balanço de poder entre as nações e da forma como o equilibro global se desenrolava - toda permanência ou transformação por parte de Pequim era fruto de movimentos estratégicos cuidadosamente estudados.

Em um memorando de 1972, escrito por Kissinger, encontramos uma definição excepcional desta complexa e sofisticada mentalidade:

Essas pessoas são, simultaneamente, fanáticas e pragmáticas. Eles são ideólogos inflexíveis e discordam totalmente de nós em relação à direção que o mundo segue ou deveria seguir. Ao mesmo tempo, eles são realistas férreos, 


\section{artigos}

Jorge Arbage

calculam que precisam de nós por causa de uma União Soviética ameaçadora, de um Japão ressurgente, e de uma Taiwan potencialmente independente (DOCUMENT 193, 1972; tradução nossa) $)^{5}$.

Para os chineses, "realistas férreos", estabelecer contato com os EUA ia além de uma necessidade estratégica. Como Washington, Pequim desejava rearranjar o equilíbrio global. Em abril de 1971, o embaixador do Paquistão entregou a Kissinger uma carta escrita à mão por Zhou Enlai, na qual se lia que o governo chinês se dispunha a receber publicamente algum emissário especial, ou até mesmo o próprio presidente, para discussões e encontros.

Menos de três meses depois, este encontro ocorreria. Secretamente, Kissinger visitou Pequim, em julho. Longe dos olhos do mundo, o diplomata partiu escondido em um avião rumo a uma terra isolada do Ocidente e sobre a qual conhecia, como ele mesmo reitera, absolutamente nada. Pela primeira vez, um emissário do mais alto escalão do governo americano visitava a China maoísta. Dois dias depois, ele enviaria um relatório a seu chefe cuja primeira frase era: "Nós lançamos as bases para que você e Mao virem uma página da história".

\section{A viagem secreta de Kissinger}

O breve encontro secreto com Zhou foi significativo e produziu dois resultados de grande importância ${ }^{6}$. Além da oficialização da viagem presidencial, há a surpreendente posição chinesa em relação a Taiwan. Por duas décadas, este fora o principal empecilho entre os dois países. Para a surpresa dos americanos, Zhou disse que Taiwan não era pauta obrigatória, até mesmo deixou subentendido que, se fosse

\footnotetext{
${ }^{5}$ Kissinger escreve: "A China estava na clássica tradição europeia. Os líderes comunistas chineses, de forma fria e sem emoção, avaliavam as exigências do balanço de poder, com pouca influência ideológica ou sentimental. Eles eram cientistas do equilíbrio, artistas da relatividade": Kissinger (1982), p.50.

${ }^{6}$ Para mais, ver Document 139 (1971).
} 


\section{artigos}

\section{A diplomacia triangular}

o caso, aquele tema não precisaria sequer ser discutido de início. Antes, a questão de Taiwan era pré-condição para o estreitamento de relações; agora, poderia ser discutida durante - ou até mesmo após - os futuros encontros. Ao menos por ora, Chiang Kai-Shek seria preterido em prol do objetivo em comum de Washington e Pequim: impedir a hegemonia de uma só nação sobre a Ásia.

Em 15 de julho de 1971, Nixon chocou o mundo por meio de um discurso transmitido ao vivo pela televisão. A viagem de Kissinger a Pequim, realizada seis dias antes, foi revelada e foi anunciado que o presidente dos Estados Unidos visitaria a China antes de março de 1972. Em seu discurso, Nixon reiterou a visão de que só poderia haver uma paz global durável e estável com a participação chinesa:

Tenho a profunda convicção que todas as nações ganharão com a redução das tensões e um melhor relacionamento entre os EUA e a RPC. É com esta intenção que eu iniciarei aquilo que, eu espero, seja uma jornada rumo à paz. Paz não somente para nossa geração, mas para as gerações futuras... (NIXON, 1971; tradução nossa).

É difícil imaginar alguma situação hipotética em nossos tempos que possa se assemelhar a seu anúncio: Richard Nixon, o homem que construíra sua carreira no anticomunismo, iria ao coração da terra de Mao, o grande revolucionário de sua época. Em Tóquio, Taipei, Moscou e Hanói, todos foram pegos de surpresa, uma historiadora notou, Nixon "chocou os aliados americanos", "enfureceu os poucos amigos da China e preocupou a União Soviética" (MACMILLAN, 2008, p.xvii). Como Gaddis (2005, p. 155) tão bem escreveu, a abertura com a China colocou os Estados Unidos na invejável posição de serem capazes de jogar seus adversários da Guerra Fria uns contra os outros. Anos depois, Nixon (1991) definiria sua visita à China como 
Jorge Arbage

o maior triunfo de seu governo, uma visão compartilhada até por seus opositores ${ }^{7}$.

\section{Nixon em Pequim}

Na manhã de 21 de fevereiro de 1972, o Boeing 707 presidencial pousou no aeroporto de Pequim. À beira de escada, Zhou Enlai o aguardava. O presidente escreveu em suas memórias:

Estendi a mão para apertar a sua. Só mais tarde percebi o quanto foi importante para ele. [...] Quando saímos do aeroporto, ele disse: "Seu aperto de mão atravessou o mais vasto oceano do mundo: vinte e cinco anos de falta de comunicação" (NIXON,1991, pp. 11,12).

Embora inconsciente e acidental, aquele fora um gesto de grande importância, até mesmo simbólico. Em 1954, durante a Conferência de Genebra, Zhou fora publicamente humilhado quando John Foster Dulles, o radical anticomunista secretário de estado de Eisenhower, recusou a dar-Ihe a mão8. Agora, o simbolismo daquele gesto era claro: a China seria tratada, dali em diante, como um igual pela maior potência do mundo.

“Este é um evento sem precedentes na história da relação entre China e Estados Unidos", Zhou Enlai proclamou no imenso salão do Grande Palácio do Povo. Na América, todos assistiam. A viagem à China foi o primeiro grande evento político planejado para a televisão: dos horários às roupas, tudo fora premeditado com o objetivo de gerar o maior impacto possível na audiência.

\footnotetext{
${ }^{7}$ Quando Kissinger foi se encontrar com Brezhnev em uma viagem secreta após a ofensiva nortevietnamita de maio de 1972, Nixon Ihe disse para dizer ao líder russo que a aliança com a China fora a coisa mais importante que ele já fizera: Document 126 (1972).

${ }^{8}$ Este é um evento que marcou profundamente os chineses a ponto de tanto Kissinger quanto Nixon escreverem em suas memórias o fato de Zhou tê-lo mencionado. Na viagem secreta de Kissinger, Huang Hua o recebeu no aeroporto e disse de imediato após cumprimentá-lo: "Você sabe... em 1954, em Genebra, seu secretário de estado se recusou a dar à mão a nosso premiê": MacMillan (2008), p.193.
} 


\section{artigos}

\section{A diplomacia triangular}

Por sua vez, o impacto na população americana foi visível. Uma pesquisa Gallup (SAAD, 2017) realizada em março de 1972 nos demonstra isso. Em comparação com as mesmas perguntas, realizadas seis anos antes, é notável como a imagem da China melhorou: em 1966, menos de 1\% dos entrevistados alegavam enxergar os chineses como um povo honesto e apenas $37 \%$ os enxergava como um povo trabalhador. Após a viagem, esses números subiram para $20 \%$ e $74 \%$, respectivamente. Já a popularidade do presidente subiu de $49 \%$ para 56\% em apenas três semanas.

"O presidente está em uma posição única", Nixon diria a Kissinger após retornarem. "Ele pôde cumprir aquilo que os assim chamados liberais prometeram, porque tem a confiança da direita desse país" (DOCUMENT 126, 1972; tradução nossa). Em um país com uma poderosa ala política conservadora, somente um homem com fortes credenciais anticomunistas poderia ter feito a aproximação chinesa sem sofrer graves retaliações políticas. Até hoje há um jargão na cultura popular estadunidense: "Somente Nixon poderia ter ido a China".

O pobre de Whittier fora alcançado ao topo, erguido ao Olimpo dos grandes estadistas. Quase $70 \%$ dos americanos responderam que o presidente contribuía para a paz mundial e um jornal de Chicago escreveu que Kissinger deixou de ser "um fenômeno" para se tornar "uma lenda" (DALLEK, 2007, p.400). Seus aliados anunciavam o que seria escrito nos livros: "A Era Nixon". Na convenção republicana de 1972, o presidente foi recebido em uma atmosfera de carnaval, saudado como o criador de uma "geração de paz" (KALB, 1974, p.13).

Curiosamente, em termos substanciais, "a semana que abalou o mundo" não produziu resultados objetivos. Qual a resolução sobre Taiwan, Washington deixaria de reconhecer o governo de Taipei? 


\section{artigos}

Jorge Arbage

A resolução de questões objetivas, entretanto, era de menor importância. A viagem de Nixon se tratou acima de tudo de um elemento simbólico. Após 20 anos de distância, era necessário um período de transição. Antes de construir algo, era preciso primeiro deixar as inimizades para trás. "A relação dos Estados Unidos com Taiwan deve ser separada da nossa relação com eles [Taiwaneses]", Mao iria dizer. Para o Chairman, Kissinger era muito apressado quanto à esta questão, afinal, "para que tanta pressa? É apenas uma ilha com uma população de uma dúzia de milhões". Esta era uma questão para "daqui a 100 anos"; o foco, no momento, deveria ser outro. Como Nixon, Mao se preocupava mais com o panorama geral, com aquilo que ele denominava "questões filosóficas": “Taiwan é uma questão menor. A questão maior é o mundo" (DOCUMENT 58, 1973; KISSINGER, 2011, p.302; DOCUMENT 194, 1972; tradução nossa).

Assim, Formosa, embora pauta não resolvida, ao menos deixou de ser um inevitável obstáculo entre os países. Um exemplo sobre a forma como China e Estados Unidos lidaram com esta controvérsia está inserida no Comunicado de Xangai. É um trecho brilhantemente vago e ambivalente, no qual o governo americano se aproveita ao máximo do poder da retórica, um uso de linguagem que os americanos chamariam de "ambiguidade construtiva":

Os Estados Unidos reconhecem que os chineses de ambos os lados do Estreito de Taiwan reiteram só haver uma China e que Taiwan é parte da China. Os Estados Unidos não questionam esta posição (DOCUMENT 203, 1972; a tradução é nossa).

Como se vê, por meio deste trecho, Washington conseguiu se posicionar em terreno seguro. Primeiro, foi dado um fim oficial ao debate do reconhecimento das 


\section{artigos}

A diplomacia triangular

"Duas Chinas". Em segundo, os Estados Unidos colocam ambos, o PCCh e o Kuomitang, em pé de igualdade. Se reconhece a China como só, mas não se diz, no entanto, qual governo é o legítimo.

O Comunicado de Xangai, assinado em 27 de fevereiro de 1972, durante a visita, lançou as bases para o estabelecimento de relações entre os dois países. Ao contrário da maioria dos documentos do tipo, ele é fundamentalmente uma lista de diferenças entre os posicionamentos políticos das duas partes. Isso faz dele algo único. Há, inclusive, um apoio declarado de Pequim ao Vietnã do Norte. Não há nem uma palavra sequer de retórica vazia em seus poucos parágrafos: EUA e China reconhecem que nada tem em comum senão o desejo de criar uma estabilidade global, um período de paz e distensão, que favoreceria a ambos. Foi o primeiro de três comunicados que levaram à uma relação que se aproxima de sua quinta década.

\section{Considerações finais}

A reaproximação entre Estados Unidos e República Popular da China é um exemplo perfeito da política externa adotada por Pequim e Washington após 1969, um caso excepcional de realpolitik calcada no realismo estratégico, o que pôde ser visto tanto nos estudos dos quatro marechais quanto na Doutrina Nixon.

Pela primeira vez desde 1945, o papel dos Estados Unidos como grande potência global era reavaliado. O mais importante a se observar do legado NixonKissinger na política externa, é a percepção de que as potências podem criar uma nova realidade, desde que saibam se adaptar de forma a tomarem as rédeas dos acontecimentos históricos e, se possível, precedê-los. Afinal, como Kissinger escreveu em sua tese de doutorado, o grande estadista jamais se rende à inevitabilidade histórica, pois o que faz sua grandeza é "a força para contemplar o caos, para 


\title{
artigos
}

Jorge Arbage

encontrar ali material para nova criação..." (Apud GRANDIN, 2017, pp.20,21).

E como os estadistas que Kissinger tanto admirava, ele e Nixon buscaram criar esta nova realidade. Após o trauma do Vietnã, a nação atingira um momento necessário de recuo e reorganização estratégica. Ao saber reinventar seu papel como nação/potência, os Estados Unidos poderiam, então, reinventar o mundo a seu redor. Acima de tudo, a reaproximação simboliza uma nova percepção de balanço global que foi levada à Casa Branca: a negação do idealismo wilsoniano e a introdução de um elemento fatalista, a crença de um mundo dividido entre interesses antagônicos, tomado pela eterna luta entre ordem e caos, no qual somente o equilíbrio entre as partes poderia levar à paz e a estabilidade. Nixon expressou sua visão de maneira clara em uma entrevista à Revista Time, após ser eleito Homem do Ano por suas conquistas na arena diplomática.

\begin{abstract}
A única época na história do mundo em que tivemos períodos de paz foi quando houve equilíbrio de poder. É quando uma nação se torna infinitamente mais poderosa em relação ao seu potencial competidor que surge o perigo de uma guerra. Creio, portanto, que será um mundo mais seguro e melhor se tivermos os Estados Unidos, a Europa, a União Soviética, a China, o Japão fortes e saudáveis, cada qual equilibrando o outro, não uns contra os outros, enfim, uma balança estável. ${ }^{9}$
\end{abstract}

Com a Diplomacia Triangular começou um período de distensão e relativa estabilidade. Este novo período, os tempos da Détente, teve impactos por todo o mundo. Evidentemente, o choque provocado pela visita de Nixon à Pequim também foi sentido na capital dos czares; provavelmente, mais forte que em qualquer outro lugar. Com a aproximação EUA-China, eles se viram encurralados pela união de seus dois maiores inimigos, um cenário que não permitia outra opção senão buscar uma

\footnotetext{
${ }^{9}$ Time Magazine, January 3, 1972. Vol. 99, n.1. Tradução nossa.
} 


\section{artigos}

A diplomacia triangular

aproximação com Washington, de forma a diminuir a tensão entre os países ${ }^{10}$.

Equilíbrio era o nome do jogo. Tratava-se de aceitar a Diplomacia Triangular, a Détente, a nova ordem global. Era uma nova forma de Contenção - mas, desta vez, a contenção não seria realizada contra os comunistas, mas com eles (GADDIS, 2005). Preocupados, os soviéticos se aproximaram dos americanos por meio dos tratados SALT e da visita de Brezhnev aos Estados Unidos. Hanói, por sua vez, se viu isolada diante deste novo contexto de distensão e, com o fracasso da ofensiva de 1972, cada vez mais fragilizada com a continuidade do conflito. Após a esmagadora reeleição de Nixon, os bombardeios de dezembro e o bloqueio do porto de Haiphong, o Vietnã do Norte finalmente cedeu às negociações e assinou os Acordos de Paz de Paris, em janeiro de 1973.

John Gaddis certa vez definiu a doutrina Nixon-Kissinger como o triunfo da geopolítica sobre a ideologia. Ao final, a aliança com a RPC permitiu que os Estados Unidos mantivessem seu papel na Ásia, apesar do fracasso na Indochina. Kissinger enxergava o triunfo do Vietnã do Norte como uma faca de dois gumes para os chineses: Hanói conquistara uma vitória ideológica que foi, ao mesmo tempo, uma derrota geopolítica (DOCUMENT 14, 1975). Como a frase demonstra, foi o que ocorreu no Sudeste Asiático: o Khmer Vermelho de Pol Pot (pró-China) ascendeu em oposição ao Vietnã do Norte (pró-URSS). Após 1975, a Ásia ficou fragmentada entre as esferas de poder russa e chinesa, dominada por uma relação de forças absolutamente frágil: esta fraqueza seria manifestada na virada de 1978 para 1979, quando o Vietnã invadir o Camboja e sofrer como consequência a invasão de seu próprio território pela China.

Esta fragmentação, contudo, poderia ser benéfica a Washington. Apesar do

\footnotetext{
10 Para mais, Document 8 (1973), Document 9 (1973) e Document 139 (1971).
} 


\section{artigos}

Jorge Arbage

Vietnã representar uma derrota ideológica de dimensões homéricas, as alianças com Pequim e Moscou permitiriam ocupar os vácuos do fragmentado poder asiático e, desta forma, compensar a retirada e derrota no continente.

Mas a estratégia que possibilitou o triunfo tinha os defeitos oriundos de suas qualidades. Aqui, tocamos em um ponto crítico: a ideia de equilíbrio global - e da necessidade de manter estáveis as esferas de poder - é elemento basilar da Diplomacia Triangular. O que precisa ser mencionado é que Nixon e Kissinger possuíam uma visão exagerada quanto aos impactos de "distúrbios" neste equilíbrio: como os escritos de Kissinger nos revelam - e isso se tornaria ainda mais claro no conceito de Linkage -, para o diplomata, o mundo vive sob uma espécie de efeito borboleta, tão absolutamente conectado que todos os problemas (mesmo os regionais) só encontram soluções diante do panorama geral do mundo. Em outras palavras: havia um certo senso de catástrofe que levou à superestimação de determinados eventos. Podemos citar, por exemplo, o Timor Leste e o Chile; ou até mesmo as consequência da retirada do Vietnã, certamente superestimadas por ambos, como De Gaulle pensava ${ }^{11}$.

Dada a visão de um mundo conectado pela interdependência entre as partes envolvidas, exigia-se um papel central da ideia de credibilidade. Posteriormente, muitos autores criticariam esse "vício" em sua diplomacia (SEBENIUS, 2018). É de suma importância citar esta visão de mundo, pois a ideia de equilíbrio global e da necessidade de manter estáveis as esferas de poder é, talvez, o elemento de maior importância na diplomacia Nixon-Kissinger e sua consequência direta é a inviolabilidade dos conceitos de força e credibilidade.

11 Também ver, Kissinger (1982), p.53. 


\section{artigos}

\section{A diplomacia triangular}

Mas o que significa credibilidade nas relações entre países? Nós podemos buscar algumas respostas em duas frases, proclamadas por dois grandes críticos. Para Hitchens, tratava-se da "necessidade de impressionar amigos e inimigos com o brio da resolução norte americana". Para Grandin (2017, p.12), tratava-se da "capacidade de ferir". Em suma: prestígio, confiança, poder; acima de tudo, a capacidade de utilizá-los. Em um de seus primeiros trabalhos, The Necessity for Choice, o acadêmico já alertava para isso, dizendo que "a posição de barganha de um país depende tradicionalmente não da lógica de suas propostas, mas também das penalidades que ele pode inferir". A paz, ele alegaria, não é conquistada sem a ameaça da guerra (Apud SEBENIUS, 2018, pp.104, 105; KISSINGER, 2012, pp. 444,446; tradução nossa).

Como resultado, a Diplomacia Nixon-Kissinger possui em seu cerne uma profunda ambivalência estratégica: ao mesmo tempo em que buscava a Détente e a paz mundial por meio da diplomacia, a Casa Branca não hesitaria em utilizar-se da força e da guerra para convencer seus inimigos da seriedade de suas intenções e da sacralidade de sua credibilidade. A Pax Americana seria mantida, em última instância, pelo uso estratégico da força (SHAWCROSS, 2002; NGUYEN, 2016).

Há também uma grave problemática moral. O objetivo da Détente era equilibrar antagonismos, de forma a produzir uma geopolítica global mais previsível e segura. Justiça não era parte de sua pauta (GADDIS, 2005). Um caso com relação direta com o tema aqui analisado é o da Guerra de Independência de Bangladesh. Em 1971, os Estados Unidos ainda buscavam se aproximar de Pequim e eram dependentes do Paquistão como único canal de comunicação com os chineses. À medida que ficou claro que a Índia iria derrotar o Paquistão, a Casa Branca passou a enxergar um cenário de hecatombe na Ásia: como em um efeito dominó cataclísmico, o triunfo 


\section{artigos}

Jorge Arbage

indiano levaria a uma inevitável guerra com a China; isto, por sua vez, poderia arrastar a URSS para um confronto. Esse entendimento levou os Estados Unidos à uma deplorável posição de apoio ao governo de Yahya Khan, mesmo com os inúmeros indícios - como o famoso Telegrama Blood - que o Paquistão realizava um genocídio de proporções assombrosas em Bangladesh ${ }^{12}$. Isso se repetirá em 1975, quando o Khmer Vermelho tomar o poder no Camboja: com a aliança chinesa já consolidada, os Estados Unidos novamente irão agir em nome do amoral balanço de poder e da realpolitik ao manter silêncio sobre as atrocidades de Pol Pot (DOCUMENT 4, 1975).

No que se trata de China e União Soviética - e, em menor medida, Vietnã -, pode-se dizer que a diplomacia Kissinger-Nixon atingiu os objetivos de suas premissas. O sucesso se refletiu na eleição presidencial de novembro de 1972, na qual Richard Nixon foi reeleito com a mais esmagadora vitória na história americana, tendo vencido em 49 de 50 estados, com uma margem de voto popular de 18 milhões de eleitores.

Todavia, o triunfo da nova ordem foi efêmero. Uma das premissas para seu sucesso eram nações fortes. O que ninguém esperava era a desgraça absoluta sob a qual a presidência americana iria cair em um período de somente dois anos. Watergate revelou os vícios e abusos de uma administração dominada pela desconfiança e pela temeridade. Nixon descobriu na pele o que era ir ao fundo do vale, após cair do topo da mais alta montanha; como em uma tragédia grega, o

\footnotetext{
12 O infame apoio a Khan está presente até no clássico de Rushdie, Os filhos da meia noite: "O presidente dos Estados Unidos, e somente ele em todo o mundo, resolveu "inclinar-se" para o Paquistão. Enquanto Henry A. Kissinger defendia a causa de Yahya Kahn, o mesmo Yahya negociava secretamente a famosa visita oficial do presidente à China...", Rushdie (2006), p.490. Também ver Isaacson (2005), p. 371-399.
} 


\section{artigos}

\section{A diplomacia triangular}

homem mais poderoso do mundo foi arrastado do triunfo à ruina por um evento que, em seu nascedouro, parecia não ter relevância alguma.

Assim, de meados de 1973 em diante, a política americana se viu progressivamente imobilizada (DOCUMENT 58, 1973). À medida que a presidência se despedaçava, os soviéticos aproveitaram o momento para expandir sua zona de influência a um ritmo que não era visto desde a era Stalin. Na Indochina, Hanói se aproveitou da morte política de Nixon para retomar a Guerra com uma nova ofensiva contra o Sul.

A Casa Branca, por sua vez, nada podia fazer, Watergate e Vietnã foram dois traumas que combinados, levaram à uma quase falência da capacidade estadunidense de conduzir sua política externa na segunda metade da década de $1970^{13}$. Houve um colapso de valores - malaise, um mal-estar da nação, Carter assim definiu. Ford e, em especial, Carter pagariam o preço por isso; ficaram ambos marcados como presidentes fracos e impotentes. Hobsbawm (2014), por exemplo, os definiria como historicamente "insignificantes".

Com a invasão do Afeganistão, em 1979, a Détente encontrou seu fim cabal. De certa forma, o fim da Diplomacia Triangular é também prova de seu triunfo - ao menos do triunfo de suas premissas. Conforme os eventos se desenrolavam, a breve decadência americana não afastou Pequim. Muito pelo contrário, o expansionismo soviético fortaleceu ainda mais a aliança com a China. Naquele mesmo ano em que os soviéticos enterravam de vez a Détente, as relações entre Washington e Pequim eram definitivamente normalizadas, o governo de Taiwan deixou de ser reconhecido e

\footnotetext{
${ }^{13}$ Não fosse Watergate, é provável que o governo de Pequim fosse reconhecido ainda no governo Nixon. Em fevereiro de 1973, Kissinger disse a Zhou que Washington deveria reconhecer a RPC até meados de 1976. Para mais, ler: Document 9 (1973).
} 
embaixadas foram abertas. Note-se, também, que desde a visita de Nixon, todos os presidentes americanos visitaram a China (a exceção foi Carter, que convidou Xiaoping).

Ao fim do primeiro encontro, Zhou e Kissinger disseram que tinham acabado de fazer história. O mundo nunca mais seria o mesmo... Quanto ao futuro desta aliança, especialmente após os acontecimentos de nossos tempos, talvez somente os chineses tenham nos provido uma frase apropriada: "É cedo demais para saber".

Fontes

ANDERSON, Perry. Duas Revoluções: Rússia e China. São Paulo: Boitempo, 2018

DALLEK, Robert. Nixon and Kissinger: Partners in Power. New York: Penguin Books, 2007.

DIKÖTTER, Frank. A grande fome de Mao. São Paulo: Record, 2017

DOCUMENT 3: Memorandum From President Nixon to his Assistant for National Security Affairs (Kissinger) Washington, February 1, 1969. Foreign Relations of the United States, 1969 - 1976, Volume XVII, China, 1969 - 1972: Document 3. Disponível em: https://history.state.gov/historicaldocuments/frus1969-76v17/d3.

DOCUMENT 4: Embassy Jakarta Telegram 1579 to Secretary State, 6 December 1975. Disponível no Kissinger Telcons em:

https://nsarchive2.gwu.edu/NSAEBB/NSAEBB62/doc4.pdf

DOCUMENT 8: Memorandum of Conversation' Beijing, February 15, 1973, 5:57-9:30 p.m. Foreign Relations of the United States, 1969-1976, Volume XVIII, China, 19731976

DOCUMENT 9 (1972): Editorial Note. Foreign Relations of the United States, 19691976, Volume IX, Vietnam, October 1972 - January 1973. Disponivel em: https://history.state.gov/historicaldocuments/frus1969-76v09/d9

DOCUMENT 9 (1973): Memorandum of Conversation, Beijing, February 16, 1973, 2:156:00 p.m. Foreign Relations of the United States, 1969-1976, Volume XVIII, China, 1973- 


\section{artigos}

A diplomacia triangular

1976. Disponível em : https://history.state.gov/historicaldocuments/frus1969-

$\underline{76 \mathrm{v} 18 / \mathrm{d} 9}$

DOCUMENT 14: MEMORAMDUM OF CONVERSATION, “Secretary's Meeting with Foreign Minister Chatchai of Thailand", 26 November 1975. Disponível nos arquivos da NSA em: https://nsarchive2.gwu.edu/NSAEBB/NSAEBB193/HAK-11-2675.pdf.

DOCUMENT 58: Memorandum of conversation, Beijing, 12 November 1973, 5:40

- 8:25 p.m. Foreign Relations of the United States, 1969-1976, Volume XVIII, China, 1973-1976: Document 58. Disponível em:

https://history.state.gov/historicaldocuments/frus1969-76v18/d58.

DOCUMENT 126: Conversation Between President Nixon and his Assistant for National Security Affairs (Kissinger), Washington, April 19, 1972. Foreign Relations of the United States, 1969-1976, Volume XIV, Soviet Union, October 1971-May 1972: Document 126.

Disponivel em:

https://history.state.gov/historicaldocuments/frus1969-76v14/d126

DOCUMENT 139: Memorandum of Conversation, Beijing, July 9, 1971, 4:35-11:20 p.m. Foreign Relations of the United States, 1969-1976, Volume XVII, China, 19691972: Document 139. Disponivel em: https://history.state.gov/historicaldocuments/frus1969-76v17/d193 
DOCUMENT 193: Memorandum From the President's Assistant for National Security Affairs (Kissinger) to President Nixon, Washington, February 19, 1972. Foreign Relations of the United States, 1969-1976, Volume XVII, China, 1969 - 1972: Document 193.

Disponível

em: https://history.state.gov/historicaldocuments/frus1969-76v17/d193.

DOCUMENT 194: Memorandum of conversation: Beijing, February 21, 1972, 2:50 3:55 p.m. Foreign Relations of the United States, 1969 - 1976, Volume XVII, China, 1969-1972: Document 194. Disponível em:

https://history.state.gov/historicaldocuments/frus1969-76v17/d194.

DOCUMENT 203 (Shanghai Communiqué): Joint Statement following Discussions with Leaders of the People's Republic of China, Shanghai, February 27, 1972. Foreign Relations of the United States, 1969-1976, Volume XVII, China, 1969 - 1972: Document 203. Disponível em: https://history.state.gov/historicaldocuments/frus1969-76v17/d203.

FERGUSON, Niall. Kissinger: 1923 - 1968: The Idealist. Nova York: Penguin Books, 2016

FINKELSTEIN, James A. An Examination of the Treaties Governing the Far-Eastern SinoSoviet Border in Light of the Unequal Treaties Doctrine. In: Boston College International and Comparative Law Review .445, Volume 2, 1979.

FRAVEL, M. Taylor. Regime Insecurity and International Cooperation: Explaining China's Compromises in Territorial Disputes. In: International Security, Vol. 30, No. 2 (Fall 2005), pp.46-83.

GADDIS, John Lewis. Cold War. New York: Penguim Books, 2005.

GERSON, Michael S. The Sino-Soviet Border Conflict: Deterrence, Escalation, and the Threat of Nuclear War in 1969. Defense Threat Reduction Agency, November 2010.

GRANDIN, Greg. A sombra de Henry Kissinger. Rio de Janeiro: Anfiteatro, 2017.

HALDEMAN, H.R. The Ends of Power. London: Sidgwick \& Jackson, 1978.

HITCHENS, Christopher. O Julgamento de Henry Kissinger. São Paulo: Boitempo, 2002. 


\section{artigos}

A diplomacia triangular

HOBSBAWM, Eric J. A Era dos Extremos: o breve século XX: 1914-1991. São Paulo, Companhia das letras, 2015.

INTELLIGENCE REPORT: MAO'S RED GUARD DIPLOMACY / POLO XXXI: 1967 (JUNE 21, 1968). Memorando da CIA, disponível nos arquivos virtuais da Agência em: https://www.cia.gov/library/readingroom/docs/polo-21.pdf. Acessado em 26 de outubro de 2020.

ISAACSON, Walter. Kissinger: a biography. New York: Simon and Schuster, 2005.

KALB, Marvin; KALB, Bernard. Kissinger: Volume II. Rio de Janeiro: Editora Artenova, 1974.

KARNOW, Stanley. Vietnam: A History. Penguin Books: New York, 1983.

KISSINGER, Henry. Diplomacia. São Paulo: Saraiva, 2012.

KISSINGER, Henry. Sobre a China. Rio de Janeiro: Objetiva, 2011.

KISSINGER, Henry. White House Years. New York: Simon \& Schuster, $2011 \mathrm{~b}$

KISSINGER, Henry. Years of Upheaval. London: Little, Brown \& Company, 1982.

MACMILLAN, Margareth. Nixon and Mao: The Week That Changed The World. New York: Random House, 2008.

NGUYEN, Viet Thanh. "Kissinger: The View From Vietnam". The Atlantic, 27 de novembro de 2016.

NIXON, Richard M. “Asia After Viet Nam”. In: Foreign Affairs, Vol. 46, No. 1, 1967.

NIXON, Richard. Inaugural Address, January 20, 1969. Texto na integra disponível em: https://avalon.law.yale.edu/20th_century/nixon1.asp

NIXON, Richard. Na Arena: vitória, derrota e recomeço. São Paulo: Siciliano, 1991.

NIXON, Richard. Report by President Nixon to the Congress: Washington, February 18, 1970. Foreign Relations of the United States, 1969-1976, Volume I, Foundations of Foreign Policy, 1969-1972: Document 60.

NIXON, Richard. Speech, July 15, 1971. Disponível em: https://china.usc.edu/richardnixon-announces-he-will-visit-china-july-15-1971 
PO-TA, Chen. Mao Tsé-Tung na Revolução Chinesa. São Paulo: Raízes da América, 2017.

REPORT: JULY 11, 1969. “Report by Four Chinese Marshals, Chen Yi, Ye Jianying, Xu Xiangqian, and Nie Rongzhen, to the Central Committee, 'A Preliminary Evaluation of the War Situation' (excerpt)", July 11, 1969, History and Public Policy Program Digital Archive, Zhonggong dangshi ziliao [CCP Party History Materials], no. 42 (June 1992), pp. 70-75. Disponível nos arquivos digitais do Wilson Center em: https://digitalarchive.wilsoncenter.org/document/117146.pdf?v=81762c8101f0d237b2 1dca691c5824e4

REPORT: SEPTEMBER 17, 1969. “Report by Four Chinese Marshals, Chen Yi, Ye Jianying, Nie Rongzhen, and Xu Xiangqian, to the Central Committee, 'Our Views about the Current Situation' (Excerpt)", September 17, 1969, History and Public Policy Program Digital Archive, Zhonggong dangshi ziliao, no. 42 (June 1992), pp. 8486. Disponível para acesso público nos arquivos digitais do Wilson Center em: https://digitalarchive.wilsoncenter.org/document/117154.pdf?v=7ac377d7a2546d86b $\underline{46 f 111693 f 4 e a 7 b}$

SAAD, Lydia. "Gallup Vault: Nixon's China Visit Was a Game Changer, February 17, 2017". Disponível em: https://news.gallup.com/vault/204065/gallup-vault-nixon-china-visitgame-changer.aspx. Acessado em 20 de junho de 2020.

SALMAN, Rushdie. Os filhos da meia-noite. São Paulo: Companhia das letras, 2006.

SCHRAM, Stuart. Mao Tse-Tung. Rio de Janeiro: Biblioteca Universal Popular, 1968.

SEBENIUS, James K. et al. Kissinger: The Negotiator: Lessons from Dealmaking at the Highest Level. New York: HarperCollins, 2018.

SERVICE, Robert. Stalin: a Biography. Londres: Pan Books, 2010

SHAWCROSS, William. Sideshow: Kissinger, Nixon, and the destruction of

Cambodia. New York: First Cooper Square Press, 2002. 